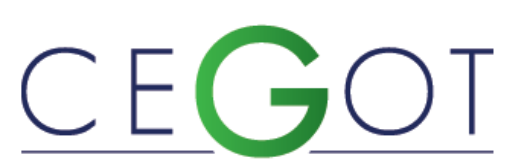

Centro de Estudos de Geografia e Ordenamento do Território
Geografia e Ordenamento do Território, Revista Eletrónica Centro de Estudos de Geografia e Ordenamento do Território http://cegot.org KLUCK, ERICK

Unicamp, IGE, Departamento de Geografia Rua Dom Viçoso, 284, 35420-000, Mariana,MG, Brasil erick@usp.br

\title{
Planejamento estatal de perspectiva territorial no campo baiano
}

\author{
State planning of territorial perspective in baiano field
}

Referência: Kluck, Erick (2019). Planejamento estatal de perspectiva territorial no campo baiano. Revista de Geografia e Ordenamento do Território (GOT), n. 16 (março). Centro de Estudos de Geografia e Ordenamento do Território, p. 153-176, dx.doi.org/10.17127/got/2019.16.007

\section{RESUMO}

Tentaremos neste artigo desdobrar um pouco alguns aspectos relativos à ascensão da "perspectiva territorial" no planejamento, a partir de algumas ações empreendidas por meio do Estado no contexto atual, como um caráter transformado do próprio capital e de sua reprodução. O planejamento estatal (e outras ações), em seus aspectos práticos constitutivos, parece assim, intimamente relacionado a uma nova requalificação da reprodução capitalista, acarretando transformações na ordem do conflito, centralização e monopolização do capital, não sustentadas sem a sua contínua incursão (do Estado), não só legislativa, como estrutural, voltada inclusive, a conformação de um sistema financeiro, no qual, determinadas atividades industriais, agropecuárias e de extração em geral, e suas infraestruturas, são privilegiadas.

Palavras-chave: planejamento estatal; território; zoneamento ecológico econômico; conflito.

\section{ABSTRACT}

In this article we will try to unfold some aspects related to the rise of the "territorial perspective" in planning, based on some actions undertaken by the State in the current context, as a transformed character of capital itself and its reproduction. State planning (and other actions), in its practical constitutive aspects, thus seems closely related to a new requalification of capitalist reproduction, leading to transformations in the order of conflict, centralization and monopolization of capital, unsupported without its continuous incursion. State), not only legislative, but also structural, aimed at conformation of a financial system, in which certain industrial, agricultural and extraction activities in general, and its infrastructures, are privileged.

Keywords: State planning; territory; economic ecological zoning; conflict. 


\section{Introdução}

A partir dos anos 1990 no Brasil, as perspectivas teóricas e de planejamento voltadas aos Eixos de Desenvolvimento e Zoneamentos Ecológicos e Econômicos, colaboraram para a transformação da ação estatal, colocando-a em direção à perspectiva territorial, apesar dessas trilharem ainda os caminhos e paradigmas de desenvolvimento centrados numa "rivalidade" Local versus Global (Santos, 2000).

A partir dos anos 2000, a incorporação de outras questões, relativas à identidade, cidadania, governança e arranjos produtivos locais, à discussão territorial, transformou as proposições estatais, planos e programas, ganhando esse, um caráter cada vez mais difuso por territórios.

As transformações não só por via direta do planejamento, mas, por meio de outras ações estatais, atravessando e compondo com elas, se coloca assim cada vez mais centralmente à reprodução ampliada do capital. Tais transformações ou novas ênfases, não se descolam de um processo social, relativo à ampliação do desenvolvimento das forças produtivas e da conformação de um mercado de capitais, como o seu sustentáculo. E, nesse processo, diversos grupos sociais são posicionados e gestados, mobilizados, constrangidos e confinados, por meio de um rol de ações dependentes de crédito estatal, sejam elas, garantidoras de sua permanência transformada na terra, ou, promotoras de sua expulsão por processos de supressão de suas terras de uso comuns e posses.

Essa forma atual do planejamento tem parte de sua fundamentação teórica em diferentes autores, que entendem as mudanças recentes como um ganho de autonomia civil e crise dos regimes autoritários, no qual a democracia e a governança colaboram com a autodeterminação cultural e territorial dos povos. Porém, esse caráter também é criticado por outros, por revelar imposições, voltadas às diretrizes de mercado, ao invés de serem posicionadas por quem experimenta as relações no lugar.

Nesse sentido, apesar da luta pela autonomia ser importante, apaga-se outra vez, o fato da autonomia ser sempre relativa, e do território e a identidade, tornados ações estatais, não deixarem de carregar as contradições da forma social de mediação, na qual se envolve o 
dinheiro, o trabalho e o próprio Estado, tais categorias de mediação social se posicionam, justamente, no processo histórico envolvendo, o próprio Estado, em muitos casos, corresponsável, pela supressão das possibilidades de reprodução do trabalho e da cultura no território. Ou seja, cada vez mais o Estado, por meio de ações e planos centrados no capital fictício, tenta gestar a crise, da qual participa.

Perguntamos: essa abrangência interpretativa não nos informaria sobre o fato de ambas as perspectivas deixarem de lado justamente o caráter crítico categorial da relação, conformado por formas sociais de mediação como dinheiro, mercadoria, trabalho, as quais, ao não serem problematizadas em sua raiz, permitem arranjos políticos satisfatórios a cada uma das interpretações, tanto da sociedade civil, quanto do Estado, aparente e concretamente contrapostas? Vejamos como se processou a implementação da perspectiva territorial do planejamento e da ação estatal na Bahia, na tentativa de ampliar essa reflexão.

\section{Aspectos teóricos sobre a ascensão da perspectiva territorial}

No Brasil, muito se discute o viés crítico alçado com a geografia. O geógrafo Milton Santos, em seus estudos e pesquisas, por exemplo, propunha uma centralidade à Geografia no quadro das ciências capazes de transformar a sociedade, dada nos conceitos de espaço geográfico e território. Ele um grupo de geógrafos do Laboratório de Geografia Política e Planejamento Territorial (LABOPLAN) da Universidade de São Paulo, fortalecendo essa noção, lançaram em 2000 o texto: O papel ativo da geografia um manifesto (Santos et al., 2000)

Segundo eles, a Geografia por muito tempo reproduziu um "limitante rol de relações homem-meio" com as teorias das localizações e dos polos, porém, hoje, para o alcance "abrangente da totalidade" deveria "considerar o espaço geográfico não como sinônimo de território, mas como território usado: e este é tanto o resultado do processo histórico quanto a base material e social das novas ações humanas" (Santos et al., 2000, p. 104).

Voltado ao território, usado e vivido, "frente" ao econômico, essas discussões internas ao amplo campo da Geografia propunha os meios de se reencontrar com o nível do cotidiano, 
da reprodução, da população, do desigual e do excluído, como disciplina capaz de mostrar a produção desigual do espaço como revelação das desigualdades na relação social ${ }^{1}$.

Denunciar a desigualdade através da crítica material do espaço, com o conceito de território usado, cerne da potencial reapropriação do expropriado, e de autogovernança sobre o espaço se tornaram as mais recentes preocupações da atividade de alguns geógrafos. Nesse sentido, "o território usado constitui-se como um todo complexo onde se tece uma trama de relações complementares e conflitantes. Daí o vigor do conceito, convidando a pensar processualmente as relações estabelecidas entre o lugar, a formação socioespacial e o mundo" (Santos et al., 2000, p. 104). Essa crítica do território usado via a possibilidade de outro planejamento, observando as falhas do anterior e denunciando o favorecimento de determinadas classes da sociedade, uma perspectiva de transformação e desenvolvimento.

A discussão entorno da categoria território, seguiu também "rumos" diferentes na Geografia, mais vinculados a problematização do poder, do simbólico e da identidade. Um autor cada vez mais importante na discussão sobre território e identidade, com uma grande produção acadêmica sobre o assunto é o geógrafo Marco Aurélio Saquet. Para ele, a concepção multidimensional, material e imaterial do território tem, entre suas características conformadoras, a identidade:

\begin{abstract}
Os homens tem centralidade na formação de cada território: cristalizando relações de influência, afetivas, simbólicas, conflitos, identidades, etc. Tanto os processos identitário como os conflituosos e transformativos são históricos e relacionais e, ao mesmo tempo, materiais e imateriais. A própria identidade é substantivada por relações desiguais e por diferenças o que, contraditoriamente, torna mais complexas e dificulta nossas atividades de pesquisa e leitura dos fenômenos e processos territoriais. (Saquet, 2015, p. 81)
\end{abstract}

A questão territorial, segundo afirma, tem sido tratada como lócus da possibilidade de luta e de investimentos em meio a uma adequação do planejamento. $E$, o território e a territorialidade seriam aspectos da dimensão do humano no espaço, de suas ações e relações, pelas quais vivencia e ocupa uma fração do planeta. Nesse sentido, ele olha para a dimensão do concreto e das microrrelações, dos poderes, não só das instituições, mas de um em relação ao outro. Dessa forma, todo território emana um poder, e prevê uma

\footnotetext{
1 “A compreensão do espaço geográfico como espaço banal obriga-nos a perceber a inter-relação entre os fenômenos. Uma perspectiva do território usado conduz a ideia de espaço banal, o espaço de todos, todo o espaço. [...] Esse é o espaço de todas as dimensões do acontecer, de todas as determinações da totalidade social. [...] temas que o real nos impõe como objeto de pesquisa e de intervenção" (Santos et al., 2000, p. 104).
} 
possibilidade de autonomia frente a outros poderes. Algo a ser considerado nas análises geográficas e do planejamento.

Frente a isso, no entanto, o geógrafo Bernardo Mançano alerta ser necessário um entendimento cuidadoso desses conceitos, principalmente ao considerar o modismo entorno da discussão sobre território. Esse passaria cada vez mais ao centro das atenções recentes, "utilizado por diversas ciências que se ocupam dos processos de produção do espaço" (Fernandes, 2015, p. 196). Assim, pretende que esse conceito ajude a

\begin{abstract}
compreender como as diferenciações da produção espacial e territorial são organizadas e reproduzidas e por quais relações e classes sociais. [...] Por essa compreensão é que entendemos ser importante o uso de uma tipologia de territórios. Relações e classes sociais produzem diferentes territórios e espaços que as reproduzem em permanente conflitualidade. (Fernandes, 2015, p. 197)
\end{abstract}

Portanto, o uso do conceito de território precisa envolver as conflitualidades conformadoras da sua produção e reprodução, ou seja, as disputas territoriais, na qual "o sentido da disputa [pelo poder] está na essência do conceito de território, que contém como princípios: soberania, totalidade, multidimensionalidade, pluriescalaridade, intencionalidade e conflitualidade" (Fernandes, 2015, p. 199).

O "reencontro" do conceito de território foi proposto também antes na "geografia crítica" fora do Brasil. Discorrendo sobre o caráter territorial das relações de poder, Claude Raffestin discutiu a questão territorial, pensando o território como um conceito crítico. Em seu livro Por uma geografia do poder, afirmou, o território é

o produto dos atores sociais. São esses atores que produzem o território, partindo da realidade inicial dada, que é o espaço. Há, portanto, um 'processo' do território, quando se manifestam todas as espécies de relações de poder, que se traduzem por malhas, redes e centralidades cuja permanência é variável, mas que constituem invariáveis na qualidade de categorias obrigatórias. (Raffestin, 1993, p. 7-8)

Ao argumentar sobre o "pacto territorial", criticava também a geografia regional lablacheana e o planejamento regional, entendendo, ser "inteiramente da lógica do Estado construir uma imagem de diversidade que ele assenta sobre a uniformidade. A região é dita, não vivida. [...] Para o estado, a região é uma expressão da qual se conserva sábia e sutilmente a polissemia" (Raffestin, 1993, p. 182-183) ${ }^{2}$. Segundo ele, este planejamento ao

\footnotetext{
${ }^{2}$ Esse caráter relativo ao Estado que afirma a região, foi discutido por Francisco de Oliveira, em seu livro Elegia para uma Re(li)gião, ao criticar entre outros, os geógrafos do planejamento, que viam a disparidade regional, como articulação de modos de produção em desigualdade. A região era assim, para ele, tornada um objeto do planejamento, e assim, região como sinônimo de região planejada. Contudo, ele mostrava que o que estava
} 
"dar voz" ao território, o transforma em informação, em "território abstrato e representado, isto é, deixa-se ver todos os fenômenos particulares e confusos e esconde-se o essencial que se torna organizado" (Raffestin, 1993, p.203).

Tal crítica tornou-se importante nos circuitos acadêmicos e não acadêmicos, pois problematizava a função do Estado no capitalismo, ao propor que a transição das atenções voltadas ao território (antes ao desenvolvimento da região), não poderia ser realizada somente pelo Estado, mas precisaria derivar de um deslocamento da esfera de poder desse para a sociedade civil.

Sua crítica ao Estado no capitalismo, pelo uso do conceito de território como empoderamento, lugar da identidade e da autonomia, passou, de certa maneira, a informar os debates e as ações de diferentes organizações não governamentais, grupos, associações de luta contra as "forças do Estado" pelo autocontrole de suas ações. Segundo ele,

é, portanto, uma 'geografia da autonomia' que está em causa. Não se trata de privilegiar o indivíduo, mas de lhe permitir conservar sua identidade e sua diferença na coletividade à qual pertence. Para tanto, ele deve poder dispor dos instrumentos teóricos que lhe permitem analisar as relações de poder que caracterizam o corpo social do qual é membro. [...] A análise geográfica do poder que extrai das ciências do homem os seus conceitos fundamentais deve, então, enfrentar aquilo que se convencionou chamar de 'atualidade' aparentemente incoerente e incompreensível. Se não o faz, não pode existir como conhecimento científico vivo. (Raffestin, 1993, p.268-269).

Colaborava assim para a constituição de "novos marcos" de um debate crítico na geografia sobre a ação estatal e políticas territoriais.

Em uma perspectiva parecida, as questões territoriais passariam também ao centro das preocupações de Rogério Haesbaert. Segundo ele, em seu livro chamado $O$ mito da desterritorialização, o território é constituído por relações de poder, revelando um domínio e apropriação em constante processo: a territorialização ${ }^{3}$.

Enfatizando a necessidade de um olhar sobre os processos concomitantemente atuantes de desterritorialização e reterritorialização, ambos de âmbito político, econômico e cultural, o

posto para a dinâmica estatal da ação planejada, a ultrapassava contraditoriamente, e estava na ordem dos conflitos postos pelo capital monopolista. Dessa forma, desmistificava o caráter do regional como objeto de ciência e o colocava como desdobramento da realidade contraditória do capital.

${ }^{3} \mathrm{O}$ "território visto por muitos numa perspectiva política ou mesmo cultural, é enfocado aqui numa perspectiva geográfica, intrinsecamente integradora, que vê a territorialização como processo de domínio (político-econômico) e/ou de apropriação (simbólico-cultural) do espaço pelos grupos humanos" (Haesbaert, 2004, p.16). 
autor entende a dimensão territorial, como um espaço de construção da autonomia e do possível desenvolvimento de políticas públicas, construídas num diálogo conjunto com quem de fato vive no lugar. E, em relação ao poder, diz que territorializar é sempre relação desigual de poder, mas a qual se poderia ter o controle. Desse modo, "quando definimos o território dos outros, de forma imposta, eles não estão de fato se territorializando, pois ser 'territorializado' por outros, especialmente quando completamente contra nossa vontade e sem opção, significa desterritorializar-se" (Haesbaert, 2004, p.262).

Ao mesmo tempo em que o território passa a ser entendido como o lugar de expressão da identidade e da cultura, da autonomia, e como espaço possível da luta (dos movimentos sociais, organizações e associações com apoio de instituições pela terra), tudo isso entremeado pela questão do poder, ele se torna, o mote das políticas de desenvolvimento territorial efetivada, nos últimos anos pelo Estado.

\section{A perspectiva territorial da ação estatal na Bahia}

Nos anos 2000, um conjunto de medidas de planejamento das ações estatais se centraram no desenvolvimento de arranjos produtivos locais (APLs) e a organização de mercados competitivos, prescindindo da organização em setores localizados. Algumas delas, inclusive modificando a base espacial de atuação (ampliada a um espectro territorial) foram reunidas no instrumento denominado Carta Europeia do Ordenamento do Território. Esta posteriormente subsidiou o programa LEADER e a metodologia da Food and Agriculture Organization of the United Nations (FAO), denominada Diagnóstico Territorial Participado e Negociado (DTPN).

Todas essas iniciativas e discussões passaram à pauta de ação do Instituto Interamericano de Cooperação Agrícola (IICA), contribuindo para a elaboração de novos modelos de ações de desenvolvimento territorial, no sentido da superação das desigualdades, num contexto globalizado, principalmente na América Latina.

A Carta Europeia do Ordenamento do Território (CEOT), colocava que, ordenar o território, era adequar à utilização conforme a sua vocação: “[...] é compatibilizar o desenvolvimento 
socioeconômico equilibrado das regiões com a melhoria da qualidade de vida, com a gestão responsável dos recursos naturais, com a utilização racional dos solos" (DGOT, 1988, p. 4)

O planejamento, sintetizando, deveria ser harmonioso, equilibrado e racional, divididos em áreas de atuação, com destaque para as "regiões rurais" . E a coordenação, feita em níveis: local, regional, nacional e europeu. Além disso, precisaria atentar à necessária cooperação política, balizada na forma da Assembleia Parlamentar e da Conferência Permanente dos Poderes Locais e Regionais da Europa.

A ênfase dada ao desenvolvimento rural, considerando principalmente as áreas mais subdesenvolvidas e periféricas, foi o mote utilizado nos programas e planos influenciados pela CEOT, inclusive na América Latina, através do Instituto Interamericano de Cooperação Agrícola (IICA). O debate, por meio do IICA, colaborou para a aprovação em 2003, no Brasil da Lei 10.683/03 na qual, entre as atribuições Ministério da Integração Nacional e da Defesa, caberia a elaboração do ordenamento do território nacional.

Em 2010, na Bahia, foram instituídos os Territórios de Identidade. Conforme observamos em nossa pesquisa, a cultura e a economia, foram centrais à delimitação geográfica e configuração do caráter de pertencimento, e assim, conformando o conceito de identidade cultural. A identidade e o território parecem de fato, inspirar e subsidiar o planejamento recente, pois de acordo com as proposições e práticas do programa baiano, a identidade se forja, tanto por meio do incentivo, através de editais de financiamento, de manifestações culturais de determinados povoados (incluindo músicas, dança e outras artes), ou seja, buscando afinidades tradicionais e culturais identitárias, quanto, por aspectos econômicos, de organização da produção, constituição de associações ou empreendimentos produtivos (SEI, 2018, p. 177-198).

A promoção de outras ações territoriais, se relacionam também aos instrumentos de planejamento e ordenamento territorial denominados de Zoneamento EcológicoEconômico (ZEE), sendo esses e suas repercussões agora analisados.

Em maio de 2012, foi instituída, a Lei Federal no 12.651 (conhecida como Novo Código Florestal), que apesar de dispor sobre a proteção e conservação da vegetação nativa, trazia em seu artigo 13, no 2 ำ parágrafo, a seguinte indicação: “Os Estados que não possuem seus Zoneamentos Ecológico-Econômicos - ZEEs segundo a metodologia unificada, estabelecida 
em norma federal, terão o prazo de 5 (cinco) anos, a partir da data da publicação desta Lei, para a sua elaboração e aprovação" (Planalto, 2014).

Na Bahia, logo após a aprovação dessa Lei, a Secretaria de Planejamento e a de Meio Ambiente, iniciaram os estudos e pesquisas para sua efetivação. Trata-se de outro conjunto de ações estatais planejadas (e outras não necessariamente planejadas), compondo o quadro contraditório e conflituoso da ação estatal geral na Bahia. Como a diretiva do planejamento estadual, desde 2010, são os Territórios de Identidade, houve uma sobreposição articulada dessas iniciativas, assim justificada:

Os mapas das zonas por territórios de identidade demonstram as peculiaridades de cada uma das duas formas de divisão espacial. Os territórios de identidade foram constituídos pelas convergências culturais, sociais e históricas de um conjunto de municípios. As zonas ecológico-econômicas se formaram com base nas convergências geoambientais e de uso do solo. [...] observa-se que o zoneamento ecológico-econômico do Estado gerou um zoneamento ecológicoeconômico dos territórios de identidade. Alguns territórios têm até cinco ou seis zonas ecológico-econômicas. [...] Espera-se que a identificação das zonas nos territórios de identidade sirva de suporte ao planejamento e gestão dos mesmos. (ZEE-BA Zoneamento, 2016)

Apesar de o foco ser a sustentabilidade, não deixa de lado o desenvolvimento econômico, e, tornado um instrumento estatal de planejamento estratégico, potencializará outras transformações no uso do território. Nesse sentido, conforme o documento intitulado "Caracterização dos Territórios de Identidade", do site de divulgação e informação sobre o ZEE-BA, esta estratégia "requer uma abordagem integrada e compartilhada de políticas públicas e arranjos institucionais, promovendo a articulação de ações e políticas territoriais, estruturadas em uma arquitetura de governança que relacione o poder público, o segmento econômico e a sociedade civil organizada, no planejamento e na gestão do seu território" (ZEE-BA, 2016, p. 21).

Além disso, segundo esse documento, há o destaque para o tipo e forma do planejamento a ser implementado, relacionado diretamente com as políticas territoriais já em curso na Bahia, inclusive, com influência teórica da perspectiva territorial:

a Bahia representou um dos estados pioneiros no processo de planejamento territorial, hoje consolidadas na forma de Regiões Administrativas, Regiões de Influência Urbana e Territórios de Identidade. Entende-se por território de identidade uma região onde as características econômicas, culturais, ecológicas, políticas e sociais se apresentam convergentes. Segundo HAESBAERT (2005) apud DI LAURO et al (2009), a formação de recortes regionais se configura mediante a interação sociedade-natureza, relações sociais concretas, desiguais e contraditórias entre múltiplas classes sociais, além de ideologias regionais fomentadoras de reconhecimento em maior escala. Os moldes de formação dos 
territórios de identidade buscam envolver em suas discussões as esferas públicas e a sociedade, inclusive para que esta última se torne ainda mais atuante. Esse processo confirma os princípios da democracia participativa, uma das revelações do final do século XX, plenamente presentes na realidade brasileira. (ZEE-BA, 2016, p. 22)

Todo esse novo plano, ainda em processo de implementação, inclusive com audiências públicas em curso, tem gerado muitas discussões e deixado os movimentos sociais atentos quanto às propostas. Isso porque, neste pacote, há abertura para implementação de ramos como mineração, logística de transportes, energia eólica, entre outros, implicando, assim, mudanças nas relações de trabalho e da apropriação da terra, gerando muitos conflitos com as comunidades, principalmente por terem suas terras suprimidas ou o uso dificultado por essas iniciativas.

No mesmo site onde constam as diretrizes, missão e objetivos do ZEE-BA, existem documentos, bastante detalhados, sobre as ações e suas potencialidades e recomendações de implantação, do qual extraímos alguns excertos para observação. Primeiro, quanto às medidas sociais, direcionadas a alguns municípios do Território do Velho Chico e de outros Territórios de Identidade, identificados como de alta vulnerabilidade social, foram destacadas as seguintes ações: educação, regularização fundiária, geração de emprego e renda, políticas para combater a vulnerabilidade social, entre outras.

As ações propostas pelo ZEE-BA em muito coincidem com as dos Territórios de Identidade, e conformam, a nosso ver, o conjunto de medidas referidas ao confinamento territorial, tornado atributo estatal gestacional da crise, como discutiremos mais adiante. Porém, na sequência, há uma guinada em relação a elas, quando destaca as potencialidades territoriais econômicas, a nosso ver, capazes de gerar diversos conflitos. Para uma aproximação disso, extraímos excertos de dois documentos do ZEE-BA: um sobre o "Cenários Tendenciais" e outro sobre as "Potencialidades e limitações" da implementação atual. Conforme o documento relativo ao Cenário de implantação da ZEE no Estado, chama a atenção a questão dos investimentos na Bahia em duas áreas, a mineração e produção de energia eólica, somando cerca de 30 bilhões de reais, e tentativa de geração de 6.000 postos de trabalho.

Estes investimentos em muito afetam as comunidades tradicionais e seus territórios, inclusive, porque a maioria dessas comunidades tem no uso comum da terra, alvo desse incentivo, a baliza de sua tradicionalidade. 
A criação de 6.000 postos de trabalho, relacionados a essas atividades de mineração e energia eólica, indica os rumos da mobilização do trabalho na área da implantação desses projetos. A ideia desse plano é elevar a Bahia a terceiro produtor de minerais do país, e para isso os investimentos serão de grande monta. Entre as justificativas para tal empreendimento estão, "a atividade mineradora concentra-se no Semiárido baiano e sua dinamização, integrada aos demais empreendimentos locais pode contribuir para enraizar as redes produtivas, de mercado e de cooperação entre os agentes, fortalecendo o processo de crescimento e desenvolvimento econômico regional" (ZEE-BA Cenários, 2013, p. 93). Para tanto, alega a necessidade de investimentos de bilhões de reais também em infraestrutura logística e de produção de energia: "simultaneamente o órgão estatal orienta investimentos em infraestrutura complementar de acesso às áreas e escoamento da produção. A demanda por infraestrutura de transporte, aliada à demanda por maior oferta de energia figuram entre os principais fatores limitantes ao crescimento da mineração baiana" (ZEE-BA Cenários, 2013, p. 93). Portanto, a dinâmica do planejamento estatal, de faceta territorial e ecológica, prevê uma ação consorciada e de grande porte para satisfação da reprodução do capital.

Em relação à energia Eólica, no documento sobre as potencialidades, se destaca o baixo impacto da implantação, dada a possibilidade de consórcio com agropecuária, e a potencialidade de ventos na Bahia 4 .

A energia eólica de fato tem sido um dos ramos em crescimento no estado da Bahia. Ao compor de forma importante o ZEE, percebemos o quanto se torna um elemento estratégico do planejamento, com uma cadeia produtiva em implantação, proposta, logo após, a discriminação das suas potencialidades, no Atlas do potencial Eólico da Bahia (Camargo-Schubert et al., 2013).

\footnotetext{
4 “A Desenvix implantou o primeiro Complexo Eólico em Brotas de Macaúbas. A Renova Energia investiu R\$ 1,2 bilhão na construção do maior Complexo Eólico do Brasil, localizado nos municípios de Caetité, Igaporã e Guanambi. A empresa espanhola Gamesa iniciou a produção de turbinas eólicas no polo industrial de Camaçari com investimento de $\mathrm{R} \$ 50$ milhões e vai produzir, nesta primeira etapa, nacelles 10 com capacidade para 300 MW/ano, um total de 150 unidades/ano. A empresa francesa Alstom está implantando sua primeira fábrica de aerogeradores das Américas na Bahia com investimentos de $\mathrm{R} \$ \mathbf{5 0}$ milhões tendo capacidade instalada de 300 MW/ano. A empresa americana General Electric Energy já assinou um protocolo de intenções com o governo da Bahia para se tornar a terceira a fabricar aerogeradores na Bahia, com investimento inicial projetado de $\mathrm{R} \$$ 45 milhões. A dinamarquesa Vestas, a maior do mundo no setor de energia eólica, também negocia com o governo da Bahia com o objetivo de realizar produção local. A empresa Torrebrás, subsidiária brasileira da espanhola Windar Renovables, pretende instalar a primeira fábrica de torres eólicas no Estado" (ZEE-BA Potencialidades, 2016, p. 548).
} 
A potencialidade e os investimentos em mineração, logística e energia eólica, ainda são permeadas por outra iniciativa do planejamento estratégico, agora em âmbito Federal. Trata-se do território estratégico do MATOPIBA, elaborado pelo Grupo de Inteligência Territorial Estratégica (GITE) da EMBRAPA. Suas ações em prol da agropecuária comercial de médio e grande porte deixam pouco ou nenhum espaço, para as pequenas e menos ainda aos posseiros. Segundo GITE, o MATOPIBA é caracterizado "pela expansão de uma fronteira agrícola baseada em tecnologias modernas de alta produtividade [...] tem como objetivo principal dar apoio técnico e científico da Embrapa ao INCRA em questões de governança e inteligência territorial estratégica" (GITE, 2016).

Essas ações, mesmo não retirando diretamente os posseiros de suas posses familiares, suprimirão suas áreas de uso comum, por meio de empreendimentos nas chapadas ou mesmo tornando essas áreas reservas legal particulares, através do dispositivo de Cota de Reserva Ambiental (CRA) instituído pela lei 12.651 de 2012 (nos artigos 15 e 44). Ou seja, essas terras ao constituírem as CRAs, podem ser vendidas aos interessados, em geral, "proprietários" de outras áreas nas chapadas no MATOPIBA. E, mesmo indiretamente, diversas áreas, poderão sofrer sua influência.

Esse conjunto de ações, somado ao que propõe os Territórios de Identidade, sobre o desenvolvimento das comunidades, potencializa tanto os riscos de supressão de seus territórios, quanto as envolve em circuitos de comércio e incentivo a produção - cada vez mais dependentes dos transportes, energia e matérias primas (se pensarmos nos maquinários e embalagens) - tornando o ordenamento, zoneamento e planejamento territorial estatal, uma ação coerente e racional do Estado.

Esta gestão compõe o papel assumido cada vez mais pelo Estado atualmente, da qual deriva o confinamento territorial. Nas descrições, o caráter talvez, apenas ambiental, denota sua funcionalidade de mercado e as ações a serem empreendidas:

Potencial para geração de energia solar (média anual de horas de insolação diária)/ Potencial para cana-de-açúcar irrigado (etanol) / Alto potencial eólico em maior parte da zona. Potencialidades na área de Turismo: Esta localizada na Zona Turística do Caminhos do Oeste e Vale do São Francisco, com potencial para o turismo ecológico Potencialidade Mineral: Rochas Fosfáticas, Talco. (ZEE-BA Zona 6 , 2014) 
Trata-se de uma tipificação especializada tornada ao mesmo tempo, uma potência de investimento, de transformação do território. Tudo isso, com o financiamento ou incentivos e subsídios estatais (marcados, entre outras coisas, pela dedução de impostos).

Essas transformações, no entanto, denotam o momento atual, no qual, a mobilidade do trabalho, por si, já se torna um caráter anacrônico. Ou seja, apesar de efetivamente se realizarem, por meio da desapropriação, despossessão, expropriação e exploração, se remetem categorialmente a um contexto de maior desenvolvimento das forças produtivas e atuação do capital fictício, como base da reprodução social fetichista. Assim, envolvendo a criação de uma superpopulação relativa, sem a funcionalidade anterior, se torna um produto crítico da forma social de mediação posta em processo de descartabilidade. Tratase da produção de sua própria negação, ou seja, ampliação de uma população para o trabalho, sem sua posterior incorporação no processo de produção. Esse se tornou o caráter da modernização em curso, com qualidade transformada, na qual as relações particulares de produção se envolvem em uma trama contraditória e crítica da reprodução social, a qual o Estado aparece como gestor da crise.

Este caráter, é o cerne da territorialização das suas ações (cada vez mais sua forma de ser) pelas quais, ao mesmo tempo, envolve as frações territoriais, nas quais, parte da população permanece "sob sua tutela", através de diversas políticas públicas, constrangidas e confinadas. A terra como território interessa a diferentes grupos, empresariais e da sociedade civil organizada, como ponte de acesso ao dinheiro e crédito mediado pelo Estado.

\section{Conflitos relacionados ao planejamento territorial}

Em 2011, Roberto Malvezzi da Comissão Pastoral da Terra - BA (CPT-BA), percebeu o aumento do processo migratório em Juazeiro "onde 30 mil pessoas se aglomeram para trabalhar como mão de obra barata nos projetos de irrigação da cana, manga e uva" (Malvezzi, 2011). Antes, em 2007, no seminário Olhares sobre a revitalização da bacia do 
São Francisco, esta questão esteve presente junto com a do aumento da violência ${ }^{5}$. Essa realidade provoca diversas manifestações dos movimentos sociais em tensão com as políticas de irrigação, responsáveis por modificar a estrutura fundiária e transformar as relações de trabalho.

A quantidade de terras em operação nos polos de irrigação, leiloadas, mas não em uso, é bem menor se comparada com a desapropriação ocorrida. Ou seja, esse fato, não consegue esconder, a transformação fundiária em curso, a imposição do deslocamento e mudanças no trabalho ${ }^{6}$. Tal contradição entre a parca utilização dos lotes leiloados e o impedimento do acesso dos antigos posseiros desapropriados, contribui para uma "liberação" de força de trabalho e sua não total absorção como força de trabalho mobilizada (Gaudemar, 1977).

Diversos são os casos empíricos observados pela Comissão Pastoral da Terra no Vale. Um deles infelizmente vivenciado pela população da área do projeto do Baixio de Irecê (do Polo de Irecê). Lá, os moradores foram desapropriados de suas terras, onde viviam como posseiros (inclusive das terras de uso comum), com indenizações muitos baixas. Na busca pela sua reprodução, alguns procuraram as empresas beneficiadas com essas terras, na tentativa vender sua força de trabalho. No entanto, dos 58.659 hectares do projeto, na prática, terras desapropriadas, apenas 2.099 hectares estão em operação (empregando a força de trabalho). O resultado foi catastrófico, conforme apresenta a CPT de Juazeiro no artigo Projeto de irrigação no Baixio do Irecê expulsa pequenos produtores. Nesse perguntava: "o que se pretende fazer com as 18 comunidades afetadas, que perfazem um total aproximado de 800 famílias e 5.000 pessoas, que já estão na insegurança, e não só quanto ao futuro? Este futuro é a mão-de-obra barata nas empresas agrícolas, a marginalidade econômica e social?" (CPT, 2008).

\footnotetext{
5 “Má qualidade dos empregos gerados na irrigação: próximos aos perímetros de Juazeiro e Petrolina formaram-se bairros inteiros (quem conhece Juca Viana sabe) onde as populações empregadas na irrigação aglomeram-se para sobreviver. Paga-se mão de obra sazonal e barata. Ora morando nos bairros periféricos ora morando do lado de fora, como estranhos em terras que já foram suas (caso da comunidade de Conchas, Juazeiro, no Projeto Curaçá). Nestas "favelas rurais" são altíssimos os índices de criminalidade, prostituição e violência. Segundo me confirmou a Dra. Ana Rúbia, Promotora de Petrolina, continua a média de cinco homicídios por semana nas duas cidades" (Siqueira, 2007, p. 20).

${ }^{6}$ De um total de 732.090 ha pertencentes a CODEVASF em 2010, como áreas de polos de irrigação, estavam em operação apenas 134.211 ha. Os outros 597.879 ha apareciam como potenciais. Os dados foram conseguidos no próprio site da CODEVASF. Ver Kluck (2011).
} 
Em 2014, cerca de 200 famílias, ligadas ao MST, ocuparam parte da área deste projeto de irrigação. Conforme a CPT, antes,

as terras que foram compradas pela CODEVASF para implantação do projeto já pertenciam às famílias das mais de 15 comunidades e que na década de 1980 foram roubadas (griladas). Desta forma, estas famílias além de terem sofrido a expulsão de suas terras naquele período, no atual contexto não serão incluídas pelo Projeto de Irrigação Baixio de Irecê, bem como não poderão desenvolver a criação de animais e a produção de alimentos que tem garantido sua sustentabilidade. (CPT, 2014)

Ao desapropriar grande parte dos posseiros de terras públicas, os separam de seus meios de produção (instrumentos e terra). Estes são assim, mobilizados, em busca de novas áreas para trabalhar, sejam em terras arrendadas, novas posses, propriedades particulares ou mesmo como assalariados nas cidades. Portanto, são colocadas em situações nas quais, ou terão baixos salários (e como recompensa a possibilidade de, ao menos, se endividar); ou migrar e "tentar a sorte" noutro lugar, no qual dificilmente as possibilidades serão menos negativas.

Com essa supressão das posses familiares e comuns de posseiros e/ou restrição a territórios cada vez menores, o Estado, compartícipe dessas ações, contraditoriamente se coloca como promotor da permanência de camponeses, incentivando-os com parcos recursos subsidiados ou com benefícios e incentivos, como Pronaf, PNAE, PAA, Bolsa Família e Garantia Safra, todos oriundos de políticas e ações estatais planejadas ou não, garantindo a reprodução do trabalho, in loco, como se essa situação não fosse crítica, confinando-os territorialmente.

Portanto, o território de confinamento é constantemente ameaçado, e por isso, as lutas aprofundam sua dimensão territorial. São diversos grupos organizados: movimento dos atingidos por barragens, pela Vale, pela Bamin (Bahia Mineração), pelo Fiol (Ferrovia de Integração Oeste-Leste), entre muitos outros.

Com a recente proposição do Zoneamento Ecológico-Econômico na Bahia, as ações empresariais voltadas à implantação de modais logísticos, de mineração e de produção de energia eólica ganharam um importante aval do Estado para o direcionamento de seus recursos. No entanto, diversas mazelas são potencializadas no decurso dessa implementação, cabendo um olhar mais aproximado aos seus desdobramentos. 
Comecemos com os relativos ao modal logístico. Segundo o ZEE-BA, no documento sobre as "Potencialidades e limitações", a logística de transportes receberá cerca de R\$ 1 bilhão em investimentos, principalmente, para a construção da Ferrovia de Integração Oeste LesteFIOL (com cerca de $1.527 \mathrm{~km}$ na Bahia, entre o porto de llhéus e cidades de Caetité e Barreiras).

No documento da ZEE já citado, referente aos "Cenários Tendenciais", o item "oportunidades econômicas" da implantação desse modal, mostra que "a implantação do complexo FIOL/Porto Sul, pode colocar a Bahia na rota da logística, nacional e internacional, especialmente se o traçado da FIOL permitir ao Estado conexão com a carga do centro oeste do País" (ZEE-BA Cenários, 2013, p. 155). E, quanto às "oportunidades sociais", afirma:

Os investimentos na requalificação logística da região permitirão melhor integração do semiárido com o Estado e restante do País promovendo acesso mais rápido e seguro aos mercados e à acessibilidade a serviços públicos; As imediações das estações e do próprio eixo ferroviário atrairão um considerável contingente de população socialmente vulnerável que, informalmente ocuparão esses espaços e, por isto, gerarão uma demanda especial de investimentos estatais. (ZEE-BA Cenários, 2013, p. 155)

Ou seja, vê como positivo, a atração de "um considerável contingente de população socialmente vulnerável", não informando a existência, na tabela sobre os "riscos econômicos" e os "riscos sociais", de nenhum impacto negativo. Porém, esses são frequentes. Segundo o Ibase (2014),

\begin{abstract}
A Ferrovia de Integração Oeste-Leste faz parte do complexo logístico implantado pelo Estado para atender a demanda do setor mineral no sudoeste e do agronegócio no oeste baiano, escoando a produção para o Porto Sul em Ilhéus. A construção do Porto Sul também apresenta uma série de desrespeitos às comunidades, aumento da violência e prostituição. A materialização dos interesses do capital no espaço por meio dos grandes empreendimentos gera muitos conflitos pela terra, pela água e conflitos no trabalho. (Ibase, 2014)
\end{abstract}

No site do Movimento Estadual dos Trabalhadores Acampados, Assentados e Quilombolas da Bahia (CETA), foi divulgada uma carta direcionada ao povo da Bahia, enviada pelo movimento autointitulado Atingidos pela BAMIN-FIOL-Porto Sul, empreendimentos ligados a essa proposta logística. Destacamos alguns trechos referentes aos enfrentamentos ocorridos desde 2011:

Nós, representantes das populações atingidas pela BAMIN-FIOL-PORTO SUL, oriundos das regiões de Bom Jesus da Lapa, Caetité, [...] indignados com a situação de degradação socioambiental causada por essas empresas, MANIFESTAMOS NOSSO TOTAL REPÚDIO ao complexo de empreendimentos que está sendo implementado no Estado da Bahia para exploração e exportação de minério [...]. Milhares de famílias desde Caetité até Ilhéus estão ameaçadas de perder suas casas e campos de trabalho para a execução desses projetos [...] Mais que isso, os 
prejuízos atingirão a todos, moradores ou não das regiões impactadas. Por isso, declaramos que não queremos os 400 empregos em nome de 4000 desempregados. (CETA, 2011)

Passemos à mineração. O ZEE-BA tem como intuito, tornar a Bahia o terceiro maior produtor do país. No documento sobre os "Cenários Tendenciais" destaca na tabela sobre as "oportunidades econômicas", referidas ao Semiárido:

A produção de níquel em Itagibá, explorado pela Mirabela, é potencializada pela presença da FIOL, tornando-a uma das minas mais eficientes do mundo. Com vida útil de 20 anos, o empreendimento favorecerá a dinamização econômica da região; O Projeto Pedra de Ferro, da Bahia Mineração, com investimentos de $\mathrm{R} \$$ 3,5 bilhões e previsão de exportar 25 milhões de toneladas/ ano de minério de ferro, tem alcance regional. Com potencial para dinamização econômica tanto da zona de exploração situada em nos municípios de Pindaí e Caetité, quanto a jusante na região de Itabuna e Ilhéus, considerando os investimentos associados ao Porto Sul - terminal privativo, FIOL e os projetos de beneficiamento e pelotização da produção; Os investimentos projetados na exploração de diamantes na região da depressão sertaneja da região de Santa Luz, e de ouro em Jacobina, favorecem à inversão de recursos na região e às perspectivas de investimento em infraestrutura com a construção de um aeroporto na região. (ZEE-BA Cenários, 2013, p. 157)

Quanto aos "riscos sociais", apresenta apenas o seguinte, mais parecendo um risco ao próprio empreendimento, que uma mazela causada por ele: "Tanto as atividades turísticas, quanto as de mineração são conduzidas de modo a beneficiar pequenos e seletos grupos sociais, enquanto as populações mais vulneráveis acabam por ser exploradas a partir de seu trabalho e, muitas vezes, expulsas territorialmente em decorrência dessas atividades e, por isso, acabam se tornando um obstáculo para o bom desempenho das mesmas" (ZEE-BA Cenários, 2013, p. 153).

Atualmente, além dos riscos, esses empreendimentos potencializam os conflitos. Conforme o jornal online, Notícias da Mineração, com dados levantados pela CPT-BA, chamado: Aumenta número de conflitos sobre o uso de água do projeto da Bamin,

os conflitos relacionados ao uso da água na Bahia cresceram quase três vezes no ano passado em comparação com 2012, saltando de 8 para 21, segundo o relatório da Comissão Pastoral da Terra (CPT) e do Instituto de Geociências da Universidade Federal da Bahia, apresentado na sexta-feira (29). "Do total de casos registrados e acompanhados pela comissão em 2013, 14 deles, ou seja, a maioria, têm origem em conflitos ligados ao projeto Pedra de Ferro, desenvolvido pela Bahia Mineração (Bamin) em Caetité e Pindaí", afirma o sociólogo Rubem Siqueira, da CPT. O número se refere às disputas travadas por camponeses contra o governo, grupos empresariais e donos de fazendas, envolvendo, sobretudo, o acesso a recursos hídricos por comunidades da zona rural. (Mineração, 2014)

A opulência de investimentos e de promessas de geração de empregos e desenvolvimento, nestes termos, vem sendo questionada por entidades de apoio a luta dos posseiros na 
Bahia. Entre elas destacamos a CPT-BA. Acompanhando de perto os acontecimentos entorno da implantação das torres de energia eólica na região de Guanambi, denominada de Alto Sertão, diversas irregularidades foram encontradas na forma da aquisição das terras e mitigação dos impactos às comunidades. Vejamos algumas das consequências com mais atenção.

Em uma reportagem realizada por (Lustosa; Santana, 2014) com Thomas Bauer da CPT-BA, os seguintes pontos foram levantados, sobre as relações entre as empresas de energia eólica e as comunidades de posseiros:

os parques eólicos que ocupam imensas extensões territoriais causam grandes impactos socioambientais para as populações locais, na sua maioria comunidades tradicionais. "Além da volta da grilagem de terra, os contratos de arrendamento assinados são sigilosos, abusivos e totalmente favoráveis às empresas que na sua grande maioria nem sequer explicam o teor destes contratos e os camponeses/as são pressionados a assinar entre a casa e a porteira da roça, comprometendo toda a geração futura [...]. Sem falar que os Parques Eólicos, em grande parte financiados com investimentos públicos e entregues à mão privada, reforçam um modelo desenvolvimentista, aumentando a concentração gerando lucro para poucos", explica Thomas. (Lustosa; Santana, 2014)

Em um artigo intitulado "O avanço do capital e sua influência nos modos de vida das populações tradicionais no município de Caetité (BA)" da CPT-BA, mais alguns elementos foram apresentados:

Em outro caso, a empresa comprou terras de um suposto proprietário, sendo que a área faz parte do território da comunidade quilombola de Malhada de Maniaçú, onde cerca de 40 famílias ocupam a área há mais de 200 anos, portanto, há fortes indícios de grilagem de terra, já que o suposto dono era inexistente até então. [...] O valor a ser pago aos proprietários, estabelecido pelos contratos é de $\mathrm{R} \$ 5.000,00 /$ torre/ano. Considerando o potencial de cada torre (1,6 MW/HORA) em um único dia de funcionamento uma torre gera $\mathrm{R} \$ 4.070,40$ (valor bruto). Em resumo, um único dia de funcionamento uma torre praticamente pagaria o valor de um ano de contrato do proprietário da terra. Isso prova que o lucro e a riqueza propagandeada são apenas exclusividade da empresa, que acumula toda a riqueza e gera com sua presença o aumento das desigualdades econômicas e sociais. [...] Quanto a vigência, a cláusula quarta do contrato da Renova diz que o mesmo terá um valor de 35 anos, sendo renovado automaticamente ao final, não havendo mais interesse por parte da empresa a mesma pode rescindi o contrato sem ônus. O contrário para o proprietário, caso queira rescindir estará sujeito a multa de $5.000 .000,00$ (5 milhões de reais) e ainda pagar pelo valor de cada torre implantada, como descreve a cláusula sétima do referido contrato. (CPT-BA, 2016)

A tendência é o acirramento e a expansão das lutas e conflitos, pois uma grande soma de investimentos, dado o caráter deste potencial, chamado por alguns de "pré-sal dos ventos" (incluindo os destinados à implantação de uma fábrica de torres) estão sendo realizadas na Bahia. Conforme a Secretaria de Comunicação Social do Governo da Bahia, em um artigo 
chamado "Nova fábrica de torres eólicas na Bahia vai gerar 850 empregos em Jacobina e região" de 2015,

Por liderar a corrida pela energia renovável e limpa - com 165 usinas de energia eólica, sendo $33 \mathrm{em}$ operação - a Bahia continua recebendo novas fábricas de equipamentos e componentes industriais para a energia gerada pela força dos ventos. [...] no município de Jacobina, a 340 quilômetros de Salvador, será inaugurada a Torres Eólicas do Nordeste (TEN), com investimentos de cerca de 30 milhões de euros. $O$ empreendimento é resultado da união entre a brasileira Andrade Gutierrez e o grupo francês Alstom. [...] Com a fábrica, serão criados 250 empregos diretos e mais 600 indiretos em Jacobina e região. A planta industrial da TEN, instalada em uma área de 140 mil metros quadrados, terá capacidade para produzir 200 torres de aço para aerogeradores por ano. (SECOM, 2015)

Dado o processo em ascensão, essas ações e consequências poderão se repetir em outras áreas, com sua potencialidade já denotada no Atlas da energia eólica. Segundo o Atlas,

Localizada na região noroeste do Estado e a sudoeste do lago de Sobradinho, a Serra do Estreito possui uma extensão aproximada de $110 \mathrm{~km}$. Trata-se de uma serra estreita, retilínea, razoavelmente plana na porção elevada e com rugosidade caracterizada por vegetação principalmente arbustiva, sobre a qual a velocidade do vento atinge $8,0 \mathrm{~m} / \mathrm{s}$ a 100 metros de altura nas melhores áreas. $O$ acesso e dado pelas rodovias BA-161 e BA-225. A região e pouquíssimo povoada, e as subestações mais próximas ficam nas cidades de Barra e Xique-Xique, a 30 e $70 \mathrm{~km}$ da extremidade sul da Serra, respectivamente, com conexões para 69 kV. A capacidade instalável para a área do Mapa 7.6 e estimada em 2,4 GW em locais com ventos acima de 7,0 m/s, a $100 \mathrm{~m}$ de altura. (Camargo-Schubert, 2013, p. 79)

Ao afirmar o "pouquíssimo" povoamento, uma inverdade, esconde o fato de essas áreas serem muito usadas, como de terras de uso comuns de diferentes comunidades. Da iniciativa de Zoneamento, decorrerão, portanto, ações, como: empreendimentos minerários, agropecuários de grande porte, barragens, polos de desenvolvimento, transportes e de energia eólica levando a situações bastante complicadas para as comunidades de posseiros, por atravessarem ou se sobreporem as suas centenárias terras de uso comum.

Os empreendimentos estatais planejados ou com financiamento estatal - entre eles, os polos de irrigação, a produção de energia eólica, as barragens, a construção de ferrovias - e privados, como a produção mineral e as grandes propriedades agropecuárias, aparecem como os responsáveis por limitar os territórios dos posseiros, motivando a diminuição do tamanho da posse de terra nas comunidades. Em geral, esses posseiros, foram constantemente deslocados para esses lugares, direta ou indiretamente, no processo em que os melhores solos foram ocupados, não só com a expansão inicial do gado, mas, com as políticas públicas de incentivo a irrigação e agropecuária destinadas a grandes empresários. 
Ocupando os piores solos, estes posseiros, estão cada vez mais constritos e confinados a um território, dividindo e subdividindo suas já pequenas posses.

A constrição territorial evidencia uma ameaça as quais estão sujeitos os posseiros, com suas posses e terras de uso comum, podendo, no entanto, complicar-se ainda mais, se considerarmos os empreendimentos, em estudo, testes ou em implementação, relacionados a produção de energia eólica e mineração, tendentes a ocupar uma parte das terras de uso comum de algumas comunidades.

Portanto, na teoria essas ações do Estado, se voltam ao desenvolvimento social, ambiental, e, ao fim da disparidades e desigualdades econômicas, mas na prática, acarretam a reprodução da mesma. Desse modo, seja qual for o caminho, de caráter mais redistributivo ou mais concentrador, estas ações, ao se desdobrarem por meio de relações e categorias sociais modernas, contraditórias, mostram o quanto esse desenvolvimento significa ao mesmo tempo, uma realidade e um futuro cada vez mais sombrio, do acirramento da competição e da degradação das condições da própria sociabilidade, se apegam à ele como um único porto seguro em meio a uma avalanche.

Para as transformações de âmbito estatal, derivadas tanto do planejamento, como das iniciativas programáticas dos governos, foram centrais as mudanças nas formas do financiamento estatal de grandes projetos agropecuários, de irrigação, e infraestruturação, entre eles, balizados no capital fictício.

Os planos de implantação de polos irrigados e outras "grandes obras", aos serem formulados com vistas ao favorecimento principal dos grandes proprietários, transformavam, e, muitas vezes arrancavam os posseiros de posses, diretamente por empreendimentos estatais ou financiados pelo Estado. Desprovidos dos meios de produção, esses posseiros, tornavam-se agrilhoados a sua força de trabalho latente, como sua única mercadoria a ser vendida, constituindo o trabalho e o trabalhador, transformando a sociedade.

Atualmente, como uma tendência justaposta a essa, o Estado incentiva a permanência do camponês, por meio de créditos, benefícios, subsídios, inclusive com linhas mais personalizadas, vinculadas diretamente à posse ou propriedade da terra. Este sentido da permanência modificada, derivado da constrição territorial a qual os camponeses estão 
submetidos, remete a uma "imobilização mobilizada", qualificando uma forma de ser do Estado: o de gestor da crise, apaziguando uma relação, que dadas as suas condições, levariam a maiores tensionamentos. A "garantia" da permanência, ao aparecer como obrigação e necessidade, como dívida com os camponeses, esconde o processo violento, de uma disputa por fundos públicos, imposto nessa e em outras formas de ação, por vezes, complicando ainda mais a reprodução do trabalho.

\section{Considerações finais}

As ações estatais voltadas ao desenvolvimento social, ambiental, e, ao fim das disparidades e desigualdades econômicas, ao se basearem nessas formas sociais de mediação, podem levar, ao contrário, a um agravamento das tensões e reposição da desigualdade. Seja qual for o caminho, de caráter mais redistributivo ou mais concentrador, estas ações mostram o quanto o desenvolvimento, sob o capitalismo, significa ao mesmo tempo, o aprofundamento de uma realidade e um futuro cada vez mais sombrio, do acirramento da competição e da degradação das condições da própria sociabilidade, as quais todos nos apegamos, como um único porto seguro em meio a uma avalanche.

Esse breve percurso tentou mostrar de uma maneira geral, como uma "perspectiva territorial" foi se tornando central, conforme a própria reprodução do capital qualitativamente se transformava. No entanto, territorialização do capital permanecia obscurecida como territorialização de relações sociais autônomas, como se fossem esferas separadas da relação social do capital, na qual o poder do mais forte imperava, sem se discutir o poder contraditório das relações das categorias sociais de mediação, agindo por trás das costas dos sujeitos, que efetivam as relações (Marx, 1988). E, desse modo, parece não superar as opressões e violências da própria base do cotidiano, como o trabalho, o dinheiro, a mercadoria. E, assim, em uma incrível inversão, o conceito de território, positivado, passa, cada vez mais, a subsidiar as pretensões atuais "desenvolvimentistas" e contraditórias do Estado. 
Estado e mercado, ambos cofundados no processo social, são também, particulares formas sociais do capital, conformando, no caso em estudo, a gestão dos camponeses e de outros trabalhadores por meio de políticas públicas, tendo no dinheiro e no crédito seu cerne, derivado de uma relação social crítica e atualmente aprofundando uma dimensão territorial. Nesta dimensão, como forma da territorialização do capital, as categorias autonomizadas no processo (terra, trabalho e capital) aparecem, por vezes, como se assim não fossem, simulando uma autonomia territorial - embora fundamentalmente, conformem uma autonomia relativa posicionada territorialmente, como uma contradição entre constrição e o confinamento territorial.

A constrição territorial relaciona a mobilização do trabalho (como dupla liberdade do trabalho) e a transformação na apropriação da terra (território), reunindo ambos processos em si mesmo. Nele se vinculam também aspectos objetivos-subjetivos da reprodução do trabalho. Transformado a cada momento, esse caráter territorial desdobra-se cada vez mais em confinamento territorial, englobando as formas de incentivo da permanência, postas na contradição, entre manutenção da tradição e patrimônio versus diminuição das possibilidades de reprodução dadas pela constrição e crise do trabalho, tendo sua base no Estado, no aporte estatal com o capital fictício.

No entanto, essa permanência não é posta como dádiva, mas tem se tornado uma necessidade do capital e a forma de ser do Estado, marcando as tensões e violências dessa forma social contraditória e essencialmente desigual de reprodução. Portanto, os movimentos sociais de luta pela terra e pela permanência na terra entram em conflitos recorrentes com o Estado e com os empresários ou proprietários de terra na tentativa de garantir com que uma parte do fundo público seja destinado a essas populações no campo, incluindo aí a terra como fundo público. Tal conjunto conflituoso expressa-se, assim, territorialmente.

\section{Referências bibliográficas}

ALMEIDA, R. A. de; PAULINO, E. T. Terra e território: a questão camponesa no capitalismo. São Paulo: Expressão Popular, 2010. ISBN: 978-85-7743-148-9. 
ALVES, V. E. L. Mobilização e modernização nos cerrados piauienses: formação territorial no império do agronegócio. 2006. Tese (Doutorado Geografia Humana), Faculdade de Filosofia, Letras e Ciências Humanas da Universidade de São Paulo, São Paulo, 2006.

ANDRADE, M. C. Produção de energia e modernização do Vale do São Francisco. Revista de Economia Política. Volume 1, n. 04. São Paulo, jan.-mar. de 1984.

ANDRADE, M. C. A terra e o homem no Nordeste: contribuição ao estudo da questão agrária no Nordeste. São Paulo: Cortez Editora, 2005. ISBN: 85-249-1115-8.

CAMARGO-SCHUBERT et al.. Atlas eólico: Bahia. Curitiba: Salvador: SECTI: SEINFRA: CIMATEC/ SENAI, 2013.

CETA. Carta dos(as) Atingidos(as) pela Bamin-Fiol-Porto Sul. 2011. 2016. Disponível em: <http://cetabahia.blogspot.com.br>. Acesso em: maio de 2016.

CPT. Comissão Pastoral da Terra. Terra na Bahia e Sergipe. Cadernos do CEAS - Centro de Estudos e Ação Social, s/no. Salvador, 1976.

CPT. Famílias ocupam terras no Baixio de Irecê. CPT Irecê (BA). 2014. 2014. Disponível em: <www.cpt.ba.br>. Acesso em: junho de 2014.

CPT. Projeto de Irrigação Baixio de Irecê na Bacia do São Francisco expulsa pequenos agricultores. CPT Juazeiro (BA). 2008. 2011. Disponível em: <www.cpt.ba.br>. Acesso em: abril de 2011.

CPT-BA. Energia eólica no alto sertão qual é o desenvolvimento? CPT Irecê (BA). 2016. 2016. Disponível em: $<$ http://cptba.org.br>. Acesso em: maio de 2016.

DELGADO, G. A Questão Agrária no Brasil, 1950-2003. s/d. Disponível em: <http://disciplinas.stoa.usp.br>. Acesso em: agosto de 2015.

ENERGIA, A. 50 mil novos empregos serão gerados por energia eólica em 2016. 2016. 2016. Disponível em: <https://www.ambienteenergia.com.br>. Acesso em: junho de 2016.

FERNANDES, B. M. Sobre a tipologia de territórios. In: SPÓSITO, E. S; SAQUET, M. A. (orgs.). Território e Territorialidades: Teorias, processos e conflitos. Rio de Janeiro: Consequência, 2015. ISBN: 978-85-69437-04-8.

GAUDEMAR, J. P. Mobilidade do trabalho e acumulação do capital. Lisboa: Estampa, 1977.

GITE. Projetos MATOPIBA. 2016.2 Disponível em: <https://www.embrapa.br/gite/projetos/matopiba/index.html>. Acesso em: julho de 2016.

HAESBAERT, R. Desterritorialização: entre as redes e os aglomerados de exclusão. In: Geografia: conceitos e temas. Rio de Janeiro: Bertrand Brasil, 1995. ISBN: 978-85-28605-45-7.

HAESBAERT, R. O mito da desterritorialização. Rio de Janeiro: Bertrand Brasil, 2004. ISBN: 978-85-28610-61-1.

HARVEY, D. A Produção Capitalista do Espaço. São Paulo: Annablume, 2006. ISBN: 85-7419-496-4.

IBASE, CANAL. Cidades baianas alvos da exploração mineral. 2014. 2016. Disponível em: <http://www.canalibase.org.br/cidades-baianas-sao-alvos-da-exploracao-mineral/>. Acesso em: março de 2016.

KLUCK, E. G. J. O trabalho vai para o Brejo: mobilização, migração e colapso da modernização. 2011. Mestrado (em Geografia Humana) Faculdade de Filosofia, Letras e Ciências Humanas da Universidade de São Paulo, São Paulo, 2011.

LUSTOSA, A.; SANTANA, I. Na Bahia: energia eólica impacta comunidade. 2014. 2016. Disponível em: <http://www.canalibase.org.br>. Acesso em: maio de 2016.

MALVEZZI, R. Brasil Rural, 2011. Disponível em: <www.cptba.org.br>. Acesso em: abril de 2011.

MINERAÇÃO, Notícias da. $2014 . \quad 2016 . \quad$ Disponível em: <http://www.noticiasdemineracao.com/geral/news/1127565/curtas-aumenta-n\%C3\%BAmero-conflitos-sobreuso-\%C3\%A1gua-projeto-da-bamin>. Acesso em: maio de 2016.

OLIVEIRA, F. M. de. A metamorfose da arribaçã: fundo público e regulação autoritária na expansão econômica do Nordeste. Revista Novos Estudos, Cebrap, 1990. 2016. Disponível em: 
<http://novosestudos.uol.com.br/v1/files/uploads/contents/61/20080624_a_metamorfose.pdf>. Acesso em: maio de 2016.

PLANALTO. Lei 12.651. 2014. 2016. Disponível em: <http://www.planalto.gov.br/ccivil_03/_ato20112014/2012/lei//12651.htm>. Acesso: junho de 2016.

RAFFESTIN, C. Por uma Geografia do Poder. Ática, São Paulo, 1993. ISBN: 85-0804-290-6

SANTOS, Milton. Por uma outra globalização: do pensamento único a consciência universal. Rio de Janeiro: Record, 2000. ISBN: 9788501058782.

SANTOS, M. et al. O papel ativo da geografia: um manifesto. Revista Território, Rio de Janeiro, ano V, no 9, jul.dez. 2000, pp. 103-109.

SAQUET, M. A.. Por uma abordagem territorial. In: SPÓSITO, E. S; SAQUET, M. A. (orgs.). Território e Territorialidades: Teorias, processos e conflitos. Rio de Janeiro: Consequência, 2015. ISBN: 978-85-69437-04-8.

SECOM. Nova fabrica de torres eólicas na Bahia vai gerar 850 empregos em Jacobina. 2015. 2016. Disponível em: <http://www.secom.ba.gov.br>. Acesso: maio 2016.

SEl. Perfil dos Territórios de Identidade. Superintendência de Estudos Econômicos e Sociais da Bahia (Série territórios de identidade da Bahia, v. 3). Salvador: SEI, 2018. ISBN 978-85-8121-017-9.

SEPLAN, BAHIA. Disponível em: <http://www.seplan.ba.gov.br>. Acesso em: julho de 2014.

SIQUEIRA, R. Olhar crítico sobre o modelo de desenvolvimento do rio São Francisco. In: Anais do Seminário Olhares sobre a revitalização da bacia do São Francisco - Grupo de Trabalho do São Francisco. Salvador, 2007. 2011. Disponível em: <www.inga.ba.gov.br>. Acesso em: 20 de abril de 2011.

SOBRINHO, J. de S. Brejos da Barra: Comunidades Camponesas no Processo de Des-envolvimento do Vale do São Francisco. 2006. Dissertação (Mestrado em Geografia Humana) - Faculdade de Filosofia, Letras e Ciências Humanas da Universidade de São Paulo, São Paulo, 2006.

SPÓSITO, E. S; SAQUET, M. A. (orgs.). Território e Territorialidades: Teorias, processos e conflitos. Rio de Janeiro: Consequência, 2015. ISBN: 978-85-69437-04-8.

ZEE-BA. Caracterização dos Territórios de Identidade. Disponível em: <http://www.zee.ba.gov.br/zee/wpcontent/uploads/2016/produtos/CARACTERIZACAO_DOS_TERRITORIOS_DE_IDENTIDADE.pdf>. Acesso em: maio de 2016a.

ZEE-BA Cenários. Cenários Tendenciais. 2013. 2016. Disponível em: <http://www.zee.ba.gov.br/zee/wpcontent/uploads/2013/10/cenario/cenarios.pdf>. Acesso em: maio de 2016.

ZEE-BA Potencialidades. 2016. 2016. Potencialidades e Limitações. Disponível em: <http://www.zee.ba.gov.br/zee/wp_content/uploads/2016/produtos/POTENCIALIDADES_E_LIMITACOES.pdf>. Acesso em: maio de 2016.

ZEE-BA Zoneamento. Zoneamentos. 2016. 2016. Disponível em: <http://www.zee.ba.gov.br/zee/?page_id=416>. Acesso em: maio de 2016.

ZEE-BA Zona 6. Zona 6. 2014. 2016. Disponível em: <http://www.zee.ba.gov.br/zee/wpcontent/uploads/2013/10/zonapdf2014/Zona6.pdf>. Acesso em: julho de 2016. 